\title{
Metabólitos secundários presentes na palma forrageira: benefícios e potencialidades
}

\author{
Secondary metabolites present in forage palm: benefits and potentialities \\ Metabolitos secundarios presentes em la palma forrajera: beneficios y potencialidades
}

Recebido: 09/02/2021 | Revisado: 16/02/2021 | Aceito: 19/02/2021 | Publicado: 28/02/2021

Jose Fabio Ferreira de Oliveira

ORCID: https://orcid.org/0000-0003-3800-2741

Universidade Federal da Paraíba, Brasil

E-mail: fabioagr@outlook.com

Albericio Pereira de Andrade

ORCID: https://orcid.org/0000-0002-1223-394X

Universidade Federal do Agreste de Pernambuco, Brasil E-mail: albericio3@gmail.com

Roberta de Lima Valença

ORCID: https://orcid.org/0000-0003-1341-1602

Universidade Federal do Agreste de Pernambuco, Brasil

E-mail: robertalimav@ hotmail.com

Goretti Lucila Carneiro da Cunha

ORCID: https://orcid.org/0000-0002-9651-1774

Universidade Federal do Agreste de Pernambuco, Brasil

E-mail: gorettilucilacunha@gmail.com

Fernando dos Santos Araújo

ORCID: https://orcid.org/0000-0002-0605-1613

Universidade Federal do Agreste de Pernambuco, Brasil

E-mail: nandosantos005@hotmail.com

André Luiz Rodrigues Magalhães

ORCID: https://orcid.org/0000-0003-2211-6795

Universidade Federal do Agreste de Pernambuco, Brasil

E-mail: andre30036@gmail.com

\begin{abstract}
Resumo
Pesquisas com palma forrageira em regiões Semiáridas são movidas pela importância de sua produção de frutos e caules suculentos (cladódios), que garantem fonte de água e nutrientes em quantidade e qualidade para as pessoas e animais destes locais. Recentemente, a busca por substâncias naturais, incluindo os metabólitos secundários de plantas (MSPs), evidenciou uma quantidade expressiva desses compostos na palma forrageira, com efeitos na alimentação e saúde. Esta revisão foi baseada em resultados de pesquisas científicas realizadas por especialistas da área com o objetivo de investigar a presença dos dos MSPs e seus benefícios na saúde e na alimentação das pessoas e animais ruminantes. Foi observado efeito positivo MSPs, como antioxidantes, agindo na prevenç ão de doenças, minimizando doenças crônicas em humanos e melhorando a produção animal, ao proporcionar aumento da ingestão de nutrientes, melhoria na fermentação ruminal, diminuição do estresse oxidativo e da excreção de metano. Portanto, a habitual utilização de palma forrageira na alimentação de ruminantes no Semiárido brasileiro e sua riqueza em MSPs requerem pesquisas que assegurem a ação destes quando presentes na dieta de ruminantes. Assim, a palma forrageira merece destaque pelos seus múltiplos benefícios em relação à saúde e alimentação, além de agregar valor aos produtos de origem animal e vegetal, contribuindo com a sustentabilidade das regiões áridas.
\end{abstract}

Palavras-chave: Aditivos fitoquímicos; Alimentação animal; Flavonoides; Semiárido; Opuntia; Nopalea.

\begin{abstract}
Research with forage palm in semi-arid regions are driven by the importance of its production of juicy fruits and stems (cladodes), which guarantee a source of water and nutrients in quantity and quality for people and animals in these places. Recently, the search for natural substances, including secondary plant metabolites (MSPs), showed an expressive amount of these substances in the forage palm, with effects on food and health. This review was based on the results of scientific research conducted by specialists in the field with the aim of investigating the presence of MSPs and their benefits on the health and nutrition of people and ruminant animals. A positive effect of MSPs was observed, as antioxidants, acting in the prevention of diseases, minimizing chronic diseases in humans and improving animal production, by providing increased nutrient intake, improved rumen fermentation, decreased oxidative stress and methane excretion. Therefore, the usual use of forage palm in the feeding of ruminants in the Brazilian Semiarid region and its richness in MSPs require research to ensure their action when present in the diet of ruminants. Thus, the forage palm deserves attention for its multiple benefits in relation to health and food, in addition to adding value to products of animal and vegetable origin, contributing to the sustainability of arid regions.
\end{abstract}


Keywords: Phytochemical additives; Animal feed; Flavonoids; Semiarid; Opuntia; Nopal.

\section{Resumen}

La investigación con palma forrajera en regiones semiáridas está impulsada por la importancia de su producción de jugosos frutos y tallos (cladodios), que garantizan una fuente de agua y nutrientes en cantidad y calidad para las personas y animales de estos lugares. Recientemente, la búsqueda de sustancias naturales, incluidos los metabolitos secundarios de las plantas (MSP), mostró una cantidad expresiva de estas sustancias en la palma forrajera, con efectos sobre la alimentación y la salud. Esta revisión se basó en los resultados de una investigación científica realizada por especialistas en la materia con el objetivo de investigar la presencia de MSP y sus beneficios en la salud y nutrición de las personas y los animales rumiantes. Se observó un efecto positivo de los MSP, como antioxidantes, actuando en la prevención de enfermedades, minimizando las enfermedades crónicas en humanos y mejorando la producción animal, al proporcionar mayor ingesta de nutrientes, mejor fermentación ruminal, disminución del estrés oxidativo y excreción de metano. Por lo tanto, el uso habitual de la palma forrajera en la alimentación de rumiantes en el semiárido brasileño y su riqueza en MSP requieren investigación para asegurar su acción cuando está presente en la dieta de los rumiantes. Así, la palma forrajera merece atención por sus múltiples beneficios en relación a la salud y la alimentación, además de agregar valor a los productos de origen animal y vegetal, contribuyendo a la sostenibilidad de las regiones áridas.

Palabras clave: Aditivos fitoquímicos; Alimentación animal; Flavonoides; Semi árido; Opuntia; Nopal.

\section{Introdução}

Os metabólitos secundários de plantas (MPS) são explorados há séculos nas mais diversas funções, desde a produção de alimentos para humanos até aditivos fitoquímicos na alimentação animal. A produção destes metabólitos é estimulada pelo estresse ambiental, como a escassez hídrica e as altas temperaturas (López Palacios \& Pena Valdivia, 2020). Neste aspecto, as plantas de regiões áridas e semiáridas, como as do Nordeste brasileiro, possuem potencial para produção de MSP. As cactáceas, especialmente a palma forrageira, além de apresentarem elevada quantidade de MSP, contribuem para a alimentação humana e animal, através da produção de frutos e caules suculentos, mesmo nas épocas de maior escassez hídrica.

Os MSPs são fontes de estudos de alta relevância, com aplicações em algumas áreas, como na saúde humana, pelas propriedades farmacêuticas (Lima Neto et al., 2015; McGehee et al., 2019) e na produção agropecuária (Valenzuela-Grijalva et al., 2017; Silva et al., 2019; Yáñez-Ruiz \& Belanche, 2020; Akanmu et al., 2020). Os MSPs possuem atividades capazes de proporcionar aos animais alta performance produtiva, sendo um promotor de crescimento ao provocar mudanças benéficas na ingestão, na atividade dos microrganismos e na absorção dos nutrientes, como também contribui positivamente com os aspectos relacionados à temática ambiental, visto que reduzem a emissão de metano pelos ruminantes (Valenzuela-Grijalva et al., 2017; Ku-Vera et al., 2020).

Os MSPs são encontrados em plantas de todas as regiões (úmidas, semiáridas e áridas), em todos os constituintes das plantas (folhas, caules e raízes) e em diferentes concentrações, sendo a produção induzida por respostas aos estresses bióticos e abióticos (Isah, 2019). A alta temperatura e radiação solar, com consequentes estresses hídrico e térmico, são fatores que estimulam a produção, uma vez que frequentemente são associados ao aumento da concentração dos MSPs (Gobbo-Neto \& Lopes, 2007). Dessa forma, plantas cultivadas em regiões com esses aspectos são potencialmente fontes de MSP, a exemplo da palma forrageira, empregada na alimentação humana e animal (Andreu-Coll et al., 2019) e utilizada para nutrição e saúde (ElMostafa et al., 2014; Alves et al., 2016).

Assim, a palma forrageira ganha cada vez mais relevância na produção animal, pois além de ser fonte de alimento para os rebanhos, possui compostos químicos que podem melhorar a saúde deles e provoca redução na emissão de gases de efeito estufa como o metano (Ku-Vera et al., 2020). Sendo assim, esta revisão tem como objetivo trazer informações sobre os compostos secundários presentes na palma forrageira, bem como seus benefícios na saúde e na alimentação das pessoas e animais ruminantes. 


\section{Metodologia}

A presente pesquisa foi desenvolvida por meio de uma revisão bibliográfica de natureza qualitativa. Em pesquisas qualitativas, destaca-se a importância da interpretação e das opiniões relatadas pelo pesquisador sobre o objeto de estudo (Pereira et al., 2018). As principais bases de dados científicos foram objetos de busca para a realização deste trabalho (Scopus, Google Scholar, Scielo e Web of Sciences), além de livros e artigos de diferentes páginas da web que abordam o tema em estudo.

As palavras-chave "Metabólitos secundários", "Alimentação animal", "Flavonoides", "Semiárido", "Opuntia", "Nopalea" foram utilizadas durante a pesquisa dos artigos publicados no período de 2001 a 2021, em português, espanhol e inglês.

\section{Revisão de literatura}

\subsection{Palma Forrageira}

No Nordeste brasileiro, uma das principais plantas utilizadas na alimentação animal é um cacto conhecido como palma forrageira. As variedades cultivadas pertencem predominantemente a dois gêneros: Opuntia e Nopalea (Lira et al., 2017). É uma cultura de origem mexicana, com reconhecimento e dispersão pelos colonizadores europeus durante os séculos XIV e XV (Ochoa \& Barbera, 2017). Os primeiros exemplares chegaram ao Brasil no século XVIII, com a finalidade da produção do corante (ácido carmínico), através da propagação do inseto conhecido como cochonilha (Dactylopius cocus) (Rocha, 2012). No entanto, a produção do cacto que mais tarde vem a ser conhecido como palma forrageira teve início no século XX (Lira et al., 2017).

Sua importância está relacionada à quantidade de água e nutrientes e à adaptação às condições edafoclimáticas das regiões Áridas e Semiáridas, expressando seu potencial produtivo nos cenários climáticos presente e futuro, devido às perspectivas de aumento a cada ano da flutuação sazonal e anual das chuvas (Dubeux Jr., 2016). Entretanto, a palma forrageira possui mecanismos adaptativos de sobrevivência em regiões de clima árido e semiárido mesmo nas épocas de maior déficit hídrico. As modificações fisiológicas (metabolismo dos ácidos das crassuláceas - CAM) como a abertura dos estômatos, essencialmente à noite, quando a temperatura do ambiente se apresenta reduzida, diminuindo as perdas de água por evapotranspiração (Almeida, 2012), são características fundamentais para a adaptação da cultura às precipitações pluviais cada dia menos previsíveis.

Além das características adaptativas, a palma forrageira é uma fonte rica de nutrientes e substâncias que a tornam de fundamental estratégia na alimentação de ruminantes, sendo um alimento rico em valor energético e carboidratos, principalmente não fibrosos (Aguilar et al., 2015), apresentando potencial para utilização na alimentação de animais de alta produção (Marques et al., 2017), além de possuir uma diversidade de MSPs com propriedades farmacêuticas e industriais (Bensadón et al., 2010; Osuna-Martínez et al., 2014; Kıvrak et al., 2018; López-Palacios \& Peña-Valdivia, 2020), características que incentivam as pesquisas para sistemas produtivos mais eficientes, levando os produtores a incluí-la entre as principais plantas cultivadas em regiões Áridas e Semiáridas.

O Brasil possuía, no ano de 2017, 129.543 estabelecimentos agropecuários produtores de palma forrageira com uma área colhida de 96.9000 ha (IBGE, 2017), em sua totalidade visando a colheita de cladódios (caules suculentos) e utillização na alimentação dos rebanhos de ruminantes. Entretanto, além dos nutrientes que compõem a dieta dos rebanhos, a ação de sintetizar metabólitos secundários torna a palma forrageira uma planta com potencial que vai além da alimentação animal, a exemplo da extração de substâncias para controle de enfermidades e do uso como fibras alimentares e compostos antioxidantes naturais (Bensadón et al., 2010). 


\subsection{Metabólitos Secundários}

Os vegetais sintetizam uma abundante quantidade de substâncias e as utilizam para seu crescimento e desenvolvimento. Todavia, um grupo de compostos chamados de MSPs ou produtos secundários, surge em resposta à ocorrência de perturbações bióticas e/ou abióticas (Isah, 2019). Estas moléculas servem para uma infinidade de funções nos processos fisiológicos das plantas, como sinalizadoras de respostas e defesa. Segundo Robles-Zepeda et al. (2009), plantas superiores respondem a estímulos ambientais, ativando seu metabolismo secundário.

Os MSPs são um grupo diversificado de compostos bioativos que se relacionam à evolução de uma espécie, além de estarem associados à resistência das plantas ao estresse, permitindo seu crescimento mesmo sob influência de agentes estressantes (López-Palacios \& Peña-Valdivia, 2020). Constituem ainda o conjunto de compostos bioativos que desempenham um papel essencial nas plantas, são sintetizados por elas para sua sobrevivência ou melhor adaptação ao ambiente (Gomez, 2012).

A presença de metabólitos secundários em geral está relacionada à persistência das plantas ao meio, sendo isto atribuído ao fato destas substâncias serem tóxicas a pragas e patógenos, além de aumentar a tolerância das plantas às perturbações ambientais, como excesso ou déficit hídrico, alta ou baixa temperatura, radiação solar, entre outros (Taiz et al., 2017), fazendo com que fatores bióticos (insetos e microrganismos) e abióticos (temperatura, radiação ultravioleta, disponibilidade hídrica, nutrientes e altitude), sejam estímulos à síntese desses produtos (Gobbo-Neto \& Lopes, 2007).

As classes de metabólitos secundários incluem compostos fenólicos, alcaloides, saponinas, terpenos, lipídios e carboidratos, os quais são subdivididos em diversos outros compostos, sendo os fenólicos o maior grupo de MSPs (Hussein \& El-Anssary, 2019). Os metabólitos secundários podem ser identificados através de análises, explorando-se a utilização das plantas in natura, ou através de suas transformações farmacêuticas (Vidal et al., 2019).

Segundo Gomez (2012), os termos compostos bioativos funcionais ou fitoquímicos dizem respeito à natureza antioxidante dos alimentos, enquanto que alimentos nutracêuticos referem-se aos alimentos ou produtos alimentares que podem proporcionar benefícios saudáveis ao consumidor, incluindo a prevenção e o tratamento de algumas doenças. Os compostos não nutritivos são metabólitos secundários responsáveis em parte pelo fornecimento de substâncias favoráveis à saúde, como os antioxidantes (Heim et al., 2002), também conhecidos como alimentos funcionais, definidos pelo Ministério da Saúde sob a portaria 398 de 30 de abril de 1999, como alimento ou substância com papel metabólico ou fisiológico que o nutriente ou não nutriente tem no crescimento, desenvolvimento, manutenção e outras funções normais do organismo humano (ANVISA, 1999).

Estudos sugerem a presença de MSPs em plantas utilizadas na dieta dos povos desde o quarto século a.C., o que contribuiu significativamente para a saúde humana. $\mathrm{O}$ aperfeiçoamento dos métodos de extração destes compostos necessita de investigação, visando maximizar sua exploração (Naczka \& Shahidi, 2004).

O estudo dessas substâncias ganha relevância devido a diversas aplicações, seja como drogas medicinais (podem ser utilizadas em diferentes tipos de doença), venenos, aromatizantes e materiais para indústria (Taiz \& Zeige, 2006; Lima Neto, et al., 2015; Terço et al., 2016; Hussein \& El-Anssary, 2019). Neste aspecto, a palma forrageira é uma planta a ser consumida estrategicamente a fim de reduzir as complicações presentes nos problemas de saúde da vida contemporânea (Avila-Nava et al., 2014), pela abundância e elevada concentração de metabólitos secundários (Rocchetti et al., 2018).

Assim, plantas de regiões sujeitas à ocorrência de estresse, principalmente hídrico, produzem significativas quantidades de MSPs, elevando sua importância e já não podem ser analisadas por uma ótica simplista de produtividade de biomassa, mas como potenciais fontes de compostos essenciais para melhorar a qualidade de vida dos animais e da população destas localidades. Nesse caso, os produtores podem comercializar sua produção com valor agregado e os consumidores podem desfrutar dos benefícios proporcionados pelas substâncias encontradas na palma forrageira. 


\subsection{Metabólitos secundários em palma forrageira}

Entre muitas plantas adaptadas e cultivadas em regiões com estresse hídrico, ganha relevância a família cactaceae, em especial a palma forrageira, cultivada em diversos países de clima árido e semiárido e importante na alimentação humana e animal (Dubeux Jr., 2016), pelo seu conteúdo mineral, energético e pela presença de compostos secundários, fonte estas promissoras de antioxidantes naturais (Avila-Nava et al., 2014; Alves et al., 2017; Kıvrak et al., 2018).

Segundo Aruwa et al. (2018), as espécies de Opuntia contêm uma ampla variedade de compostos fenólicos e não fenólicos, sendo estes constituintes que exercem atividades biológicas isolada ou sinérgica. A quantidade de compostos fenólicos e flavonoides está relacionada ao poder antioxidante do extrato de frutas da Opuntia fícus indica e Opuntia streptacantha (Mabrouki et al., 2015). Tais substâncias são estruturas químicas que apresentam hidroxilas e anéis aromáticos nas formas simples ou de polímeros que proporcionam o poder antioxidante (Angelo \& Jorge, 2007).

Os flavonoides agem no sistema biológico através da neutralização dos radicais livres gerados no organismo, sendo estes associados ao câncer, tumores e doenças cardiovasculares (Soares, 2002; Santos \& Rodrigues, 2017). Os radicais livres são moléculas altamente reativas que se caracterizam pela deficiência de elétrons, atribuindo a estes o status de alta toxicidade no nível celular (Gomez, 2012), fator que justifica pesquisas referentes à extração e uso de metabólitos secundários presentes na palma e/ou nos produtos oriundos de animais consumidores de tal cactácea, como carne e leite.

A classe de metabólitos secundários mais abundante nas plantas são os compostos fenólicos derivados da fenilalanina, formando o ácido cinâmico, possuindo sua reação catalisada pela enzima fenilalanina amonialiase, sendo esta etapa reguladora importante na formação de muitos compostos fenólicos. A atividade desta enzima está diretamente relacionada aos fatores ambientais, como regime hídrico, luminosidade, níveis de nutrientes, entre outros. (Teiz \& zeiger, 2006).

Como já mencionado, as plantas de palma forrageira são fontes importantes de substâncias bioativas, o que as capacitam para a preparação nutracêutica e funcional dos alimentos. Os frutos, cladódios, sementes e flores têm alto teor de constituintes químicos, agregando valor aos produtos (Nazareno et al., 2017). Até mesmo a casca dos frutos pode constituir um reservatório promissor de compostos naturais a ser usado como alimento natural ou para fins farmacêuticos (Bourhia et al., 2019), além da mucilagem extraída da casca de frutos e cladódios, que pode atuar como emulsificante natural, agente espumante ou substâncias para as indústrias de alimentos e cosméticos (Gheribi et al., 2019).

Os metabólitos secundários são encontrados em todas as partes da planta de palma (Galati et al., 2002; Nazareno, 2017), havendo maiores concentrações nos órgãos em desenvolvimento (Taiz \& Zeiger, 2006; Taiz et al., 2017). Fato é que os altos níveis de metabólitos secundários nos estágios iniciais do crescimento podem atuar como um mecanismo de defesa, uma vez que o órgão não desenvolveu outro mecanismo defensivo, como os espinhos e gloquídeos (Ventura-Aguilar et al., 2017), tornando sua detecção facilitada nos cladódios em desenvolvimento em detrimento aos completamente desenvolvidos, conforme Tabela 1. 
Tabela 1. Detecção de substâncias químicas presentes nos extratos etanólicos brutos dos cladódios completamente desenvolvidos e em desenvolvimento da espécie vegetal Opuntia cochenillifera (L.) Mill.

\begin{tabular}{|c|c|c|}
\hline \multirow{2}{*}{ Classes } & \multicolumn{2}{|c|}{ Amostra } \\
\hline & Cladódio completamente desenvolvido & Cladódio em desenvolvimento \\
\hline Fenóis & + & - \\
\hline Taninos & - & + \\
\hline Flavonoides & - & + \\
\hline Flavononas & - & + \\
\hline Flavonóis & - & + \\
\hline Xantonas & - & + \\
\hline Saponinas & - & + \\
\hline Alcaloides & - & + \\
\hline
\end{tabular}

-: substância não detectada; +: substância detectada. Fonte: Silva et al. (2016)

Essas substâncias metabolizadas pelas plantas de palma forrageira possuem potenciais benefícios econômicos e de importância para a saúde, quando consumidos através de extratos concentrados ou através do consumo de partes da planta como brotos e frutos (Aruwa et al., 2019). Confirma-se assim, o conhecimento existente há mais de 12.000 anos, com o consumo de cactos frescos pelos nativos por suas características organolépticas e nutricionais, além das propriedades curativas (Nazareno et al., 2017).

Os compostos secundários encontrados na palma forrageira Opuntia spp. atuam na prevenção de doenças crônicas, como diabetes, doenças cardiovasculares, síndrome metabólica, obesidade ou envelhecimento, bem como doenças infecciosas ou neurodegenerativas (Dias et al., 2017). Isto foi constatado através da análise do extrato hidroalcoólico de palma forrageira que possui efeito expressivo como agente antiproliferativo de células de câncer de cólon humano, uma vez que os constituintes fitoquímicos apresentados nas amostras, nomeadamente betacianinas, flavonóides (derivados da isorhamnetina) e ácidos fenólicos (ácido ferúlico) foram identificados como os principais compostos responsáveis pelo ciclo celular (Serra et al., 2013).

Neste aspecto, a palma forrageira tem potencial de contribuir na melhoria da saúde dos povos modernos, que buscam redução das complicações associadas ao estresse oxidativo através do uso de alimentos funcionais, pois o extrato de palma forrageira possui efeito protetor a espécies reativas de oxigênio, devido à sua capacidade de neutralização (Smida et al., 2017). Segundo Willcox et al. (2004), os danos oxidativos a diferentes tipos de células e suas biomoléculas, como DNA, proteínas e lipídios, foram associados ao desenvolvimento de doenças crônicas, incluindo envelhecimento, câncer, inflamações das articulações, asma, doenças cardiovasculares e diabetes, entre outras. Este fato está relacionado ao desequilíbrio das espécies de redução-oxidação que ocasiona processos que regulam a expressão gênica em muitas doenças (Ng et al., 2018).

Além dessas funções, testes in vitro provaram que extratos de cladódio de palma forrageira possuem componentes como polifenóis e flavonoides com potencial efeito protetor contra a indução de uma substância altamente tóxica, o Chloropyrifos, causador de danos imunológicos (Smida et al., 2017) e as flores são ricas em componentes polifenólicos bioativos naturais que têm potencial para extração e uso na indústria de alimentos, como também em preparações farmacêuticas e cosméticas (Aruwa et al., 2019). Na Tabela 2, estão apresentados alguns trabalhos que identificaram os compostos presentes em variedades de palma forrageira e suas respectivas concentrações, assim como o órgão da planta onde foram encontrados.

De acordo com as informações disponíveis na literatura, a palma forrageira é uma fonte de MSPs. Frutas, cladódios, flores e sementes de O. fícus indica, são ricos em compostos funcionais para as indústrias alimentícia e farmacêutica (Tahir et 
al., 2019). Os cladódios são constituídos de flavonoides (5,8\%), fenóis $(4,1 \%)$, alcaloides $(2,05 \%)$, saponinas $(1,08 \%)$, taninos $(0,9 \%)$. Seu fruto contém flavonoides $(6,1 \%)$, fenóis $(3,38 \%)$, alcaloides $(1,75 \%)$, saponinas $(1,22 \%)$, taninos $(1,2 \%)$ e terpenoides $(0,8 \%)$ (Pooja \&Vidyasagar, 2016). Concentrações que asseguram o potencial farmacológico do uso no tratamento de doenças, principalmente as crônicas (Osuna-Martínez, et al., 2014). Estas substâncias são ingeridas durante o consumo de partes da planta (frutos, sementes ou cladódios) ou através de extratos. Todavia, nos cladódios concentra-se uma quantidade relevante de substâncias, enriquecendo a dieta das populações que os adicionam ao seu cardápio, por serem alimentos funcionais (comparáveis ao valor antioxidante dos mirtilos (Vaccinium myrtillus L.), plantas com alta concentração (Moze et al., 2011), assim como para controle de processos alimentares e segurança alimentar (Blando et al., 2019).

Tabela 2. Caracterização e concentração dos MSPs em variedades de palma forrageira.

\begin{tabular}{|c|c|c|c|}
\hline Autor/Composto Secundário & Variedade & Parte da planta & Quantidade \\
\hline \multicolumn{4}{|l|}{ Mabrouki et al. (2015) } \\
\hline Flavonoides & O. ficus-indica & Frutos & $22,47 \pm 2.1 \mathrm{mg} \mathrm{RE} * * * / 100 \mathrm{~g}$ \\
\hline Flavonoides & O. streptacantha & Frutos & $34,75 \pm 1.89 \mathrm{mg} \mathrm{RE} / 100 \mathrm{~g}$ \\
\hline \multicolumn{4}{|l|}{ Ammar et al. (2015) } \\
\hline $\begin{array}{l}\text { EC50 Atividade de } \\
\text { eliminação do DPPH }\end{array}$ & O. ficus-indica & Flores & $200,34 \mu \mathrm{g} / \mathrm{mL}$ \\
\hline \multicolumn{4}{|l|}{ Pooja \& Vidyasagar (2016) } \\
\hline Flavonoides & O. dillenii Haw & Cladódios & $32 \mathrm{mg} / 100 \mathrm{~g}$ \\
\hline Fenóis & O. dillenii Haw & Cladódios & $68 \mathrm{mg} / 100 \mathrm{~g}$ \\
\hline Alcaloides & o. dillenii Haw & Cladódios & $54 \mathrm{mg} / 100 \mathrm{~g}$ \\
\hline Saponinas & O. dillenii Haw & Cladódios & $105 \mathrm{mg} / 100 \mathrm{~g}$ \\
\hline \multicolumn{4}{|l|}{ Alves et al. (2016) } \\
\hline Taninos & $\begin{array}{l}\text { O. ficus-indica }(\text { L.) Mill e } \\
\text { N. cochenillifera }\end{array}$ & Cladódios & Diferentes intensidades \\
\hline Flavonoides & $\begin{array}{l}\text { O. ficus-indica (L.) Mill e } \\
\text { N. cochenillifera }\end{array}$ & Cladódios & Diferentes intensidades \\
\hline \multicolumn{4}{|l|}{ Kivrak et al. (2018) } \\
\hline Flavonoides & O. ficus-barbarica & Frutos & $69,237 \mathrm{mg} \mathrm{kg}^{-1}$ \\
\hline Flavonoides & O. robusta & Frutos & $66,385 \mathrm{mg} \mathrm{kg}^{-1}$ \\
\hline \multicolumn{4}{|l|}{ Blando et al. (2019) } \\
\hline Fenóis & O. ficus-indica (L.) Mill. & Cladódios jovens & $\begin{array}{c}399.61 \pm 11.98 \mathrm{GAE}^{* / 100 \mathrm{~g}} \\
\mathrm{MN}^{* *}\end{array}$ \\
\hline Fenóis & O. ficus-indica (L.) Mill. & Cladódios maduros & $160.14 \pm 8.09 \mathrm{GAE} / 100 \mathrm{~g} \mathrm{MN}$ \\
\hline \multicolumn{4}{|l|}{ Aruwa et al. (2019) } \\
\hline Polifenol & O. ficus-indica (L.) Mill. & Cladódios & $10,46 \mathrm{mg} \mathrm{GAE} * / \mathrm{g}$ \\
\hline $\begin{array}{l}\text { Poder antioxidante de } \\
\text { redução do ácido férrico }\end{array}$ & O. ficus-indica (L.) Mill. & Cladódios & $94,67 \mu \mathrm{mol} \mathrm{Fe}(\mathrm{II}) / \mathrm{g}$ \\
\hline
\end{tabular}

*GAE-Total de fenóis equivalente ao ácido gálico. **MN-Matéria Natural. ***RE- Equivalente a Rutina. Fonte: Autores.

As variedades cultivadas no Nordeste brasileiro dos gêneros Opuntia e Nopalea, são fontes de metabólitos secundários como os esteroides, compostos fenólicos, flavonoides, antocianinas, polifenóis e vitamina C (Avila-Nava et al., 2014; Alves et al., 2017). Todavia, a composição depende de muitos fatores: espécie, cultivar ou variedade; fatores ambientais, como as condições climáticas e edáficas; manejo de culturas, incluindo fertilização e tratamento pós-colheita (Alves et al., 2017; 
Nazareno, 2017), sendo importante a avaliação dos metabólitos secundários presentes nas plantas cultivadas em diferentes latitudes, o que representa uma oportunidade de interesse nos cultivos de palma do Nordeste brasileiro, potencializando o uso e estimulando o interesse na produção desta cultura.

Os frutos e cladódios coletados em diferentes regiões e estações do ano podem ser utilizados para analisar como o clima e o solo afetam a capacidade antioxidante (Alves et al., 2017; Zeghad et al., 2019). Já em relação a variedades selvagens e domesticadas de Opuntia, houve semelhança da concentração de metabólitos secundários (López-Palacios \& Peña-Valdivia, 2020), sugerindo que o processo de domesticação não altera a capacidade de formação de compostos secundários da palma forrageira, conforme concentração de ácidos fenólicos, flavonoides e terpenos apresentados na Tabela 3.

Tabela 3. Concentração de ácidos fenólicos, flavonoides e terpenos em cladódios jovens de espécies de Opuntia.

\begin{tabular}{|c|c|c|c|c|c|}
\hline \multirow[b]{2}{*}{ Compostos } & \multicolumn{5}{|c|}{ Espécies de Opuntia } \\
\hline & streptacantha & hyptiacantha & megacantha & albicarpa & ficus-indica \\
\hline & \multicolumn{5}{|c|}{ Ácidos fenólicos $\left(\mu \mathrm{g} \mathrm{g}^{-1} \mathrm{DM} \pm \mathrm{SE}\right)$} \\
\hline hidroxicinâmico & $33,59 \pm 7,38$ & $10,93 \pm 1,81$ & $12,03 \pm 4,17$ & $8,45 \pm 1,28$ & $20,51 \pm 3,06$ \\
\hline \multirow[t]{2}{*}{ hidroxibenzóico } & $62,34 \pm 7,12$ & $25.60 \pm 6,5$ & $33,21 \pm 8,35$ & $48,38 \pm 6,65$ & $79,09 \pm 7,57$ \\
\hline & \multicolumn{5}{|c|}{ Flavonoides $\left(\mu \mathrm{g} \mathrm{g}^{-1} \mathrm{DM} \pm \mathrm{SE}\right)$} \\
\hline Apigenina & $0,24 \pm 0,0$ & $0,19 \pm 0,0$ & $0,22 \pm 0,05$ & $0,22 \pm 0,12$ & $0,65 \pm 0,51$ \\
\hline Isorhamnetina & $9,51 \pm 0,08$ & - & $4,47 \pm 0,03$ & $3,31 \pm 0,35$ & $10,21 \pm 0,28$ \\
\hline Quercetina & - & $5,44 \pm 3,0$ & - & $16,83 \pm 5,41$ & $15,49 \pm 5,08$ \\
\hline \multirow[t]{2}{*}{ Rutina } & $3,57 \pm 1,02$ & $2,11 \pm 0,76$ & $4,95 \pm 1,03$ & $3,75 \pm 1,14$ & $4,90 \pm 1,26$ \\
\hline & \multicolumn{5}{|c|}{ Terpenos } \\
\hline$\beta$-Amyrin $\left(\mu \mathrm{g} \mathrm{g}^{-1} \mathrm{MS}\right)$ & $3,09 \pm 1,52$ & $4,39 \pm 1,10$ & $3,39 \pm 1,17$ & $3,09 \pm 1,56$ & $1,33 \pm 0,54$ \\
\hline $\begin{array}{c}\text { Ácido oleico }\left(\mathrm{ng} \mathrm{g}^{-1}\right. \\
\text { MS) }\end{array}$ & $22,84 \pm 18,31$ & $15,87 \pm 7,06$ & $27,19 \pm 24,01$ & $63,26 \pm 27,56$ & $13,92 \pm 9,99$ \\
\hline $\begin{array}{c}\text { Peniocerol }\left(\mu \mathrm{g} \mathrm{g}^{-1}\right. \\
\text { MS) }\end{array}$ & $0,73 \pm 0,01$ & $0,83 \pm 0,03$ & $0,74 \pm 0,02$ & $0,79 \pm 0,04$ & $0,83 \pm 0,06$ \\
\hline
\end{tabular}

-: Não detectado. Adaptado de López-Palacios \& Peña-Valdivia (2020). Fonte: Autoes.

Diante dos compostos apresentados nas tabelas 1, 2 e 3, o cultivo de palma forrageira apresenta-se como uma boa oportunidade, visando a melhoria da saúde e qualidade de vida dos consumidores, seja o consumo da planta direto na forma de cladódios jovens, chamados de nopalitos (broto comestíveis) de frutos, através de extratos concentrados produzidos pela indústria farmacêutica, ou ainda, na forma de subprodutos da cadeia de produção animal.

Além de ser fonte de compostos bioativos, a palma forrageira é uma das fontes de nutrientes fundamentais para alimentação dos rebanhos de ruminantes na região semiárida brasileira, que é uma das (se não a principal) responsáveis pela nutrição e garantia da produção de ruminantes nesta localidade, em especial nas épocas de estiagem (Oliveira et al., 2011). 
Assim, torna-se vital entender as funções dos metabólitos secundários dessas espécies, seu papel na fisiologia animal e a resposta que os alimentos oriundos desses animais podem proporcionar à saúde dos consumidores.

\subsection{Palma na alimentação humana}

As plantas com Metabolismo Ácido das Crassulácea (CAM) apoiam a produção agrícola pela sua resiliência e persistência, mesmo na ausência de precipitações pluviais significativas para o adequado crescimento de plantas com metabolismo $\mathrm{C} 3$ e C4. Culturas CAM apresentam altos rendimentos, benefícios ambientais e são ricas em nutrientes, como Agave spp., Ananas comosus e as cactáceas (Davis et al., 2019).

Entre as cactáceas, a palma forrageira é relevante para os povos de terras Áridas e Semiáridas. Como já mencionado, estas são responsáveis por suavizar os impactos das estiagens, visto que são detentoras de elevada quantidade de água em sua composição, contribuindo para a segurança alimentar das populações e dos rebanhos de ruminantes, como uma ferramenta para mitigar a seca e combater a desertificação, além de possuir compostos essenciais para a saúde dos habitantes dessas regiões (Dessimoni et al., 2014; Nefzaou et al., 2014).

No México, cladódios frescos e produtos deles derivados são alimentos frequentemente utilizados na dieta dos habitantes e também encontrados com frequência nos EUA, em especial na Califórnia. No entanto, ainda é rara sua ocorrência nos continentes europeu e asiático (Stintzing \& Carle, 2005). No cenário mundial, o Brasil e a Tunísia destacam-se na produção de cactos (Opuntia) com uma área estimada de 600 mil ha cultivados ambos, seguidos pelo México com 230 mil ha e Marrocos com 150 mil ha (Kauthale et al., 2017).

Em muitos países como Argentina, Chile, Peru, Bolívia, África do Sul, Egito, Turquia, Etiópia, Eritreia, o fruto da palma forrageira é tradicionalmente consumido (Sáenz et al., 2017), fazendo parte da paisagem natural e dos sistemas agrícolas de muitas regiões do mundo. Existe um interesse crescente nas variedades de palma forrageira, que desempenha um papel estratégico no desenvolvimento agrícola e econômico, particularmente em áreas desfavorecidas de recursos hídricos, em vista de suas oportunidades de geração de renda, produção de alimentos e conservação de ecossistemas (Nefzaou et al., 2014).

A palma é um alimento frequente na culinária mexicana, por exemplo, fazendo parte da dieta da população através do consumo de brotos (nopalitos) e/ou frutos (Shetty et al., 2012). Com excelente qualidade e sabor, frutas frescas e brotos jovens servem como prato nutritivo de legumes e saladas (Shetty et al., 2012). Os cladódios de Opuntia stricta são fonte de vitaminas, fitoquímicos, possuem óleo essencial com benefícios medicinais (Izuegbuna et al., 2019), apresentam alta atividade antioxidante, conteúdo fenólico, flavonoides, antocianinas (Alves et al., 2017) e os ácidos, gálico, cafeico, ferulico, quercetina, rutina e linoleico (López-Palacios \& Peña-Valdivia, 2020). Aos seis meses, o teor de proteína é de $94 \mathrm{~g} \mathrm{~kg}$-1; aos dois anos, é de $45 \mathrm{~g}$ kg-1. No caso da fibra, ocorre uma relação inversa: $80 \mathrm{~g} \mathrm{~kg}-1$ aos seis meses e aos dois anos $145 \mathrm{~g} \mathrm{~kg}-1$ (FAO, 2013). Desta forma, enquanto jovem, os cladódios são usados como nopalitos, porém quando mais maduros apresentam lignificação, sendo consumidos na forma de farinha.

Uma dieta com capacidade de fornecer substâncias que tenham influência na saúde, como os antioxidantes, ou que reduzam o colesterol de baixa densidade, são essências para uma vida saudável. Cladódios e frutos de palma apresentam esse perfil de ácidos graxos, de uma dieta de elevada qualidade. Neste aspecto, os cladódios desenvolvidos e as cascas dos frutos apresentam predominância de Ácido linoléico (C18: 2), que é um ácido graxo essencial e os cladódios jovens possuem o ácido palmítico (C16: 0) como o principal ácido graxo (Andreu-Coll et al., 2019). Ainda segundo a pesquisa, a palma forrageira possui perfil dos ácidos graxos encontrados nos frutos e cladódios jovens e maduros, benéficos à saúde e à alimentação por causa dos altos valores poli-insaturados e monoinsaturados.

Desta forma, os constituintes da planta, como folhas tenras em salmoura ou em conserva em vinagre (nopalito), sucos pasteurizados, doces, farinhas e uma seleção de alimentos processados menos populares, desenvolvidos para mercados do 
México e dos Estados Unidos (FAO, 2013) são usados pelos povos desses países. O consumo de alimentos derivados da palma contribui para suprir a necessidades de água e nutrientes, em especial dos habitantes de regiões que apresentam déficit hídrico, pelo alto teor de água em sua composição (mais de 90\%),

Cladódios e cascas de frutos desidratados são ricos em pigmentos (betacianinas, indicaxantinas e carotenóides) e compostos nutricionais, incluindo açúcar, proteínas e vitaminas e podem ser utilizados como corantes em alimentos (Bourhia et al., 2020). A substituição da farinha de trigo pelo pó dos cladódios ao nível de 5\% não afetou a aceitabilidade sensorial, além de ser considerado como um ingrediente funcional potencial de promoção da saúde em produtos de panificação (Msaddak et al., 2017). Farinha de cladódios pode fazer parte da composição de muitos alimentos, agregando qualidade nutricional e compostos nutracêuticos, além de melhorar as características organolépticas de produtos para produção de pão (Cândido Filho et al., 2014; Boukid et al., 2015). Apresenta também uma grande riqueza em biomoléculas que melhoram o valor nutricional e conferem estabilidade aos produtos alimentícios formulados (Ayadi et al., 2009).

Face aos resultados aqui apresentados, constata-se evidência de que a palma forrageira possui características nutricionais e diversidade de exploração tecnológica para ser considerada um alimento estratégico no futuro da humanidade, não devendo permanecer subutilizada (Vila Nova et al., 2017). Há uma vasta gama de alternativas para o processamento de frutos, cladódios e sementes da palma forrageira que apresenta constituintes com benefícios para a saúde sendo ainda fonte de nutrientes e vitaminas. Além disso, apresenta outros usos, incluindo cosméticos, produção de biocombustíveis, fitorremediação do solo e nutrição animal (García et al., 2020).

\subsection{Palma na alimentação animal}

Os ruminantes se alimentam prioritariamente de vegetais, como a palma forrageira, onde estão presentes os nutrientes requeridos e uma diversidade de MSPs que, a depender do tipo e concentração, alteram a digestibilidade e o desempenho animal. Dessa forma, em uma recente revisão, foram bem detalhados os efeitos dos MSPs na modulação ruminal, a ação de óleos essenciais, taninos e saponinas, promovendo mecanismos e modificando a fermentação (Yáñez-Ruiz \& Belanche, 2020), melhorando a conversão alimentar e elevando o ganho de peso.

Assim, a palma forrageira representa uma estratégia fundamental para alimentação dos rebanhos de ruminantes, sendo uma importante fonte de água e nutrientes. Além de ser rica em nutrientes digestíveis totais (Aguilar et al., 2015), constitui um dos principais alimentos no Semiárido brasileiro (Ferreira et al., 2009). É um alimento de elevada qualidade nutricional para animais ruminantes. Prova disso é o aumento ou manutenção da produção de carne e leite e a melhoria nas características dos produtos. São amplas as pesquisas científicas em relação à utilização dos cladódios na alimentação de ruminantes.

Eles substituem alimentos frequentemente utilizados na alimentação animal sem prejuízo para a produção. A substituição do feno de Tifton 85 por palma forrageira (in natura ou desidratada) melhora o desempenho e as características de carcaça de ovinos (Andrade e al., 2016). Para (Conceição et al., 2018), na dieta de novilhos, pode substituir até 55\% do farelo de trigo. De acordo com Oliveira et al. (2007), na dieta de vacas holandesas em lactação, substitui o milho e parte do feno do capim-tifton sem alterar a produção e a composição do leite. Em um estudo realizado com ovinos, Rezende et al. (2020), observaram que a substituição de $80 \%$ da silagem de sorgo (com 35\% de concentrado) aumentou substancialmente a ingestão de nutrientes, principalmente energia. De acordo com Monteiro et al. (2018), a utilização da palma forrageira em uma dieta com taxa de volumoso concentrado de 70:30 atendeu os requerimentos nutricionais de vacas em lactação com rendimento médio de $20 \mathrm{~kg} / \mathrm{dia}$; Knupp et al. (2019), observaram que cordeiros alimentados com palma forrageira em 50\% da dieta, tiveram aumento do consumo de matéria seca e ganho de peso médio diário. De acordo com os dados supracitados, existe volume significativo de trabalhos que recomendam o uso da palma forrageira na alimentação de ruminantes, incluindo os que recomendam substituição dos alimentos tradicionalmente utilizados, como forma de redução dos custos e garantia da produção, assegurando a importância 
dessa cultura.

Assim, a palma forrageira, além de todos os benefícios mencionados, principalmente os relativos à nutrição animal, surge como uma fonte de MSPs (Tabela 1, 2 e 3), sendo estes promotores de crescimento, melhorando o consumo, a digestão e a absorção de nutrientes, ao agirem como moduladores ruminais (Valenzuela-Grijalva et al., 2017; Yáñez-Ruiz \& Belanche, 2020). MSPs, como terpenos e flavonoides, que possuem ação benéfica em algumas espécies de microrganismos, melhoram a degradação da fibra e proteína, além de reduzirem a perda de energia alimentar na forma de metano (Ku-Vera et al., 2020). Taninos melhoram a digestibilidade da matéria seca e orgânica, nutrientes digestíveis totais e proteína bruta (Alves Junior et al., 2017). Óleos essenciais ricos e ácido gálico modificam a fermentação ruminal, promovendo aumentos na produção de leite (Blanch et al., 2016). Os polifenóis melhoram a absorção de proteínas, reduzem o nitrogênio entérico e a emissão de metano, auxiliando ainda na saúde dos animais, na qualidade do leite e de produtos lácteos (Correddu et al., 2020). Polifenóis reduzem a biohidrogenação de ácidos graxos poliinsaturados e aumentam o nível de ácido linoleico, sendo os compostos fenólicos associados aos precursores de ácido graxo poliinsaturados transferidos para os produtos lácteos (Cabiddu et al., 2019), resultando em alimentos saudáveis.

Gama et al. (2020), trabalhando com inclusão (34\%) de palma orelha de elefante mexicana (Opuntia stricta [Haw.] Haw.) na dieta de vacas leiteiras, observaram aumento expressivo nos teores dos ácidos vacênico (C18:1 trans-11), linoleico (C18:2 n-6) e rumênico (CLA cis-9, trans-11) na gordura do leite, elevando seu valor nutracêutico, uma vez que esses ácidos graxos apresentam propriedades benéficas à saúde. De acordo com os autores tal fato pode ser justificado pela redução da biohidrogenação ruminal ou a incompleta biohidrogenação dos ácidos graxos poliinsaturados, concluindo que a palma forrageira Opuntia stricta pode ser um ingrediente alimentar valioso para melhorar o valor nutracêutico do leite.

Oliveira (2017) trabalhando com palma forrageira em substituição à cana de açúcar para ovinos em terminação, observou aumento dos ácidos graxos vacênico (C18:1 trans-11) e ecosatrienóico (C20:3n3c). O ácido vacênico é um intermediário da biohidrogenação, sendo considerado um importante precursor para a síntese endógena do C18:2 cis-9, trans-11 (CLA) por ação da $\Delta 9$ dessaturase e várias espécies de bactérias que podem ser derivadas do intestino humano. Por isso, é considerado neutro ou benéfico à saúde humana (Sun et al., 2015).

A diminuição ou incompleta biohidrogenação ruminal ocorrida nos animais alimentados com palma forrageira pode estar relacionada à presença de compostos secundários deste vegetal, visto que para Vasta et al. (2019), os compostos fenólicos modulam a biohidrogenação, alterando a composição microbiana ruminal, favorecendo os fluxos ruminais de ácidos graxos poliinsaturados, trans-11 18: 1 e cis-9, trans-11 CLA à custa de 18: 0. Os compostos secundários inibem espécies de bactérias responsáveis pela lipólise dos ácidos graxos poliinsaturados (Mannelli et al. (2018), além de aumentarem a população de protozoários ruminais (Ben Salem et al., 1996). Estes, por sua vez, são fonte de 18: 2 n-6, trans-11 18: 1 e cis -9, trans-11 CLA (Yáñez-Ruiz et al., 2006).

Dietas constituídas por palma forrageira apresentam comportamento da fermentação dos carboidratos semelhante aquelas que são ricas em MSPs. Em geral, a elevada fermentação dos carboidratos e produção de gás in vitro em dietas com palma forrageira é atribuída à elevada quantidade de carboidratos não fibrosos e à baixa quantidade de fibras (FDN e FDA) (Pessoa et al., 2020). Determinados parâmetros ruminais da cinética de produção de gás incrementaram o ganho de peso em $41 \%$, quando palma forrageira foi adicionada à silagem de milho (Arreola et al., 2019). Desta forma, dietas com palma forrageira possuem maior aproveitamento ao elevarem a digestibilidade das fibras.

Assim, é imprescindível mais pesquisas com o objetivo de identificar MSPs que melhorem a performance produtiva dos rebanhos alimentados com palma forrageira. 


\section{Considerações Finais}

A palma forrageira é fonte de metabólitos secundários, que proporcionam benefícios à saúde e à alimentação de pessoas e ruminantes. Os compostos químicos encontrados na palma forrageira são potenciais promotores de crescimento na produção de ruminantes. As propriedades químicas encontradas na palma forrageira agregam valor aos produtos de origem animal, contribuindo assim para a sustentabilidade das regiões áridas. Recomenda-se maiores estudos sobre a utilização dos compostos secundários presentes na palma forrageira, o impacto causado no metabolismo animal e na emissão de gases, bem como nos produtos oriundos dos animais que os consomem.

\section{Agradecimentos}

Os autores agradecem à Coordenação de Aperfeiçoamento de Pessoal de Nível Superior (CAPES), pela concessão da bolsa de pós-graduação.

\section{Referências}

Agência Nacional De Vigilância Sanitária. ANVISA. (Brasil). Diretrizes básicas para análise e comprovação de propriedades funcionais e ou de saúde alegadas em rotulagem de alimentos. 1999. Portaria nº 398, de 30 de abril de 1999. http://bvsms.saude.gov.br/bvs/saudelegis/anvisa/1999/prt0398_30_04_1999.html.

Aguilar, P., Pires, A. J. V., Soares, M. S., Silva, L. G., Guimarães, J. O., Rocha, L. C., Machado, T. C., \& Frazão, O. S. (2015). Palma forrageira e bagaço de cana tratado com ureia e amônia na dieta de ruminantes. Revista Nutritime, 12(01), 3936-3951.

Akanmu, A. M., Hassen, A., \& Adejoro, F. A. (2020). Haematology and Serum Biochemical Indices of Lambs Supplemented with Moringa oleifera, Jatropha curcas and Aloe vera Leaf Extract as Anti-Methanogenic Additives. Antibiotics, 9, 601; 10.3390/antibiotics9090601.

Almeida, R. F. (2012). Palma forrageira na alimentação de ovinos e caprinos no semiárido brasileiro. Revista Verde, 7(4), 08-14.

Alves Júnior, R. T., Souza, E. J. O., Melo, A. A. S., Silva, D. K. A., Torres, T. R., Pereira, G. F. C., Silva, C. S., \& Silva, J. R. C. (2017). Mesquite Extract as Phytogenic Additive to Improve the Nutrition of Sheep. Journal of Agricultural Science, 9(7), 164-174. 10.5539/jas.v9n7p164.

Alves, F. A. L., Andrade, A. P., Bruno, R. L. A., Silva, M. G. V., Souza, M. F. V., \& Santos, D. C. (2017). Seasonal variability of phenolic compounds and antioxidant activity in prickly pear cladodes of Opuntia and Nopalea genres. Food Sci. Technol, 37(4), 536-543. dx.doi.org/10.1590/1678-457X.19316.

Alves, F. A. L., Andrade, A. P., Bruno, R. L. A., Silva, M. G. V., Souza, M. F. V., Pessoa, C., Oliveira, F. C. E., Brito Filho, S. G., \& Santos, D. C. (2016). Genetic diversity and seasonal chemical profile by $1 \mathrm{H}$ NMR and cytotoxic activity in Opuntia and Nopalea genres. Journal of Medicinal Plants Research, 10(40), 732-747. 10.5897/JMPR2016.6207.

Ammar, I., Bardaa, S., Mzid, M., Sahnoun, Z., Rebaii, T., Attia, H., \& Ennouri, M. (2015). Antioxidant, antibacterial and in vivo dermal wound healing effects of Opuntia flower extracts. International Journal of Biological Macromolecules, 15, 00583-8. dx.doi.org/10.1016/j.ijbiomac.2015.08.039.

Andrade, S. F. J., Batista, Â. M. V., Carvalho, F. F. R., Lucena, R. B., Andrade, R. P. X., \& Lima Júnior, D. M. (2016). Fresh or dehydrated spineless cactus in diets for lambs. Acta Scientiarum, 38(2), 155-161. 10.4025/actascianimsci.v38i2.29329.

Andreu-Coll, A. L., Lamadrid, C. M., Sendra, E., Barrachina, C. Á., Legua, P., \& Hernández, F. (2019). Fatty acid profile of fruits (pulp and peel) and cladodes (young and old) of prickly pear [Opuntia ficus-indica (L.) Mill.] from six Spanish cultivars. Journal of Food Composition and Analysis, 84, 103294. 10.1016/j.jfca.2019.103294.

Andreu-Coll, L., Cano-Lamadrid, M., Sendrac, E., Carbonell-Barrachina, A., Legua, P., \& Hernández, F. (2019). Fatty acid profile of fruits (pulp and peel) and cladodes (young and old) of prickly pear [Opuntia ficus-indica (L.) Mill.] from six Spanish cultivars. Journal of Food Composition and Analysis, 84(103294), $1-8$. org/10.1016/j.jfca.2019.103294.

Angelo, P. M., \& Jorge, N. (2007). Phenolic compounds in foods - A brief review. Rev. Inst. Adolfo Lutz, 66(1), 1-9.

Arreola, A. G., Ortiz, M. M., Carrasco, G. P., Saucedo, F. R., \& Torres, E. H. (2019). Nutritive quality and gas production of corn silage with the addition of fresh and fermented prickly pear. Journal of Animal \& Plant Sciences, 40(1), 6544-6553. http://www.m.elewa.org/JAPS.

Aruwa, C. E., Amoo, S. O., \& Kudanga, T. (2018). Opuntia (Cactaceae) plant compounds, biological activities and prospects - A comprehensive review. Food Research International, 112, 328-344. 10.1016/j.foodres.2018.06.047.

Aruwa, C. E., Amoo, S. O., \& Kudanga, T. (2019). Extractable and macromolecular antioxidants of Opuntia ficus-indica cladodes: Phytochemical profiling, antioxidant and antibacterial activities. South African Journal of Botany, 125, 402-410.

Avila-Nava, A., Calderón-Oliver, M., Medina-Campos, O. N., Zou, T., Gu, L., Torres, N., Tovar, A. R., \& Pedraza-Chaverri, J. (2014). Extract of cactus (Opuntia ficus indica) cladodes scavenges reactive oxygen species in vitro and enhances plasma antioxidant capacity in humans. Journal of Functional Foods, $10,13-24$. Doi:10.1016/j.jff.2014.05.009. 
Ayadi, M. A., Abdelmaksoud, W., Ennouri, M., \& Attia, H. (2009). Cladodes from Opuntia ficus indica as a source of dietary fiber: Effect on dough characteristics and cake making. Industrial Crops and Products, 30, 40-47. 10.1016/j.indcrop.2009.01.003.

Ben Salem, H., Nefzaoui, A., Abdouli, H., \& Orskov, E. R. (1996). Effect of increasing level of spineless cactus (Opuntia ficus indica var. inermis) on intake and digestion by sheep given straw-based diets. Animal Science, 62(2), 293-299. https://doi.org/10.1017/S135772980 0014600.

Bensadón, S., Hervert-Hernández, D., Sáyago-Ayerdi, S. G., \& Goñi, I. (2010). By-Products of Opuntia ficus-indica as a Source of Antioxidant Dietary Fiber. Plant Foods for Human Nutrition, 65(3), 210-216. 10.1007/s11130-010-0176-2.

Bispo, S. V., Ferreira, M. A., Véras, A. S. C., Batista, Â. M. V., Pessoa, R. A. S., \& Bleuel, M. P. (2007). Palma forrageira em substituição ao feno de capimelefante. Efeito sobre consumo, digestibilidade e características de fermentação ruminal em ovinos. Revista Brasileira de Zootecnia, 36(6), 1902-1909. doi.org/10.1590/S1516-35982007000800026.

Blanch, M., Carro, M. D., Ranilla, M. J., Viso, A., Vaz quezanon, M., \& Bach, A. (2016). Influence of a mixture of cinnamalde hyde and garlic oil on rumen fermentation, feeding behavior and performance of lactating dairy cows. Animal Feed Science and Technology org/10.1016/j.anifeedsci.2016.07.002

Blando, F., Russo, R., Negro, C., De Bellis, L., \& Frassinetti, S. (2019). Antimicrobial and Antibiofilm Activity against Staphylococcus aureus of Opuntia ficusindica (L.) Mill. Cladode Polyphenolic Extracts. Antioxidants, 8(117), 2-13. 10.3390/antiox8050117.

Boukid, F., Boukid, Z., \& Mejri, M. (2015). Opuntia Cladodes: Physicochemical parameters, Functional Properties and Application in Formulation of Rolled Cake of Cladode Flour Fabric (Part 2). Int. J. Adv. Sci. Eng., 1(4), 30-34.

Bourhia, M., Elmahdaoui, H., Moussa, S. I., Ullah, R., \& Bari, A. (2020). Potential Natural Dyes Food from the Powder of Prickly Pear Fruit Peels (Opuntia spp.) Growing in the Mediterranean Basin under Climate Stress. BioMed Research International, 1(1), 1-9. 10.1155/2020/7579430.

Bourhia, M., Elmahdaoui, H., Ullah, R., Bari, A., \& Benbacer, L. (2019). Promising Physical, Physicochemical, and Biochemical Background Contained in Peels of Prickly Pear Fruit Growing under Hard Ecological Conditions in the Mediterranean Countries. BioMed Research International, 1-8. $10.1155 / 2019 / 9873146$

Cabiddu, A., Continia, S., Gallob, A., Lucinic, L., Bani, P., Decandia, M., Molle, G., Piluzza, G., \& Sulas, L. (2019). In vitro fermentation of cardoon seed press cake - A valuable byproduct from biorefinery as a novel supplement for small ruminants. Industrial Crops \& Products, 130, 420-427. doi.org/10.1016/j.indcrop.2018.12.095.

Cândido Filho, A., Pereira, F. C., \& Lima, A. K. V. O. (2014). Base alimentar humana com o uso da palma forrageira: o estudo da arte. 1(1), 1-9. https://m.uniara.com.br/legado/nupedor/nupedor_2014/Arquivos/03/6_Amy\%20Lima.pdf.

Conceição, M. G., Ferreira, M. A., Silva, J. L., Costa, C. T. F., Chagas, J. C. C., \& Monteiro, C. C. F. (2018). Can cactus (Opuntia stricta [Haw.] Haw) cladodes plus urea replace wheat bran in steers' diet? Asian-Australas J Anim Sci, 31(10), 1627-1634. https://doi.org/10.5713/ajas.17.0927.

Correddu, F., Lunesu, M. F., Buffa, M. F., Atzori, A. S., Nudda, A., Battacone, G., \& Pulina, G. (2020). Can Agro-Industrial By-Products Rich in Polyphenols be Advantageously Use in the Feeding and Nutrition of Dairy Small Ruminants? Animals, 10, 131, Doi:10.3390/ani10010131.

Davis, S. C., Simpson, J., Gil Vega, K. D. C., Niechayev, N.A., Van Tongerlo, E., Castano, N. H., Dever, L.V., \& Búrquez, A. (2019). Undervalued potential of crassulacean acid metabolism (CAM) for current and future agricultural production. Journal of Experimental Botany, 1(1), 2-17. 10.1093/jxb/erz223.

Dessimoni, G. V., Batista, A. G., Barbosa, C. D., \& Dessimoni-Pinto, N. A. V. (2014). Composição bromatológica, mineral e fatores antinutricionais da palma forrageira. Tecnologia e ciência agropecuária, 8(3), 51-55.

Dubeux, Jr., J. C. B. (2016). Cactus: a crop for the dry áreas. University of Florida. n. 28.

El-Mostafa, K., Kharrassi, Y. E., Badreddine, A., Andreoletti, P., Vamecq, J., Kebbaj, M. S. E., Latruffe, N., Lizard, G., Nasser B., \& Cherkaoui-Malki, M. (2014). Nopal Cactus (Opuntia ficus-indica) as a Source of Bioactive Compounds for Nutrition, Health and Disease. Molecules, 19, 14879-14901; 10.3390/molecules190914879.

Ferreira, M. A., Silva, F. M., Bispo, S. V., \& Azevedo, M. (2009). Estratégias na suplementação de vacas leiteiras no semiárido do Brasil. Revista Brasileira De Zootecnia-brazilian Journal of Animal Science, 38(1), 322-329. 10.1590/S1516-35982009001300032.

Food and agriculture organization of the United Nations- FAO., (2013). Agro-industrial utilization of cactus pear. http://www.fao.org/publications.

Galati, E. M., Tripodo, M. M., Trovato, A., Miceli, N., \& Monforte, M. T. (2002). Biological effect of Opuntia ficus indica (L.) Mill. (Cactaceae) waste matter Note I: diuretic activity. Journal of Ethnopharmacology, 79(3), 17-21.

Gama, M. A., de Paula, T. A., Véras, A. S., Guido, S. I., Borges, C. A., Antoniassi, R., Lopes, F. C. F., Neves, M. L. M. W., \& Ferreira, M. D. A. (2020). Partially replacing sorghum silage with cactus (Opuntia stricta) cladodes in a soybean oil-supplemented diet markedly increases trans-11 18: 1, cis-9, trans-11 CLA and 18: 2 n-6 contents in cow milk. Journal of Animal Physiology and Animal Nutrition, 00, 1-15. 10.1111/jpn.13466.

García, H. F., Andreu-Coll, L., Cano-Lamadrid, M., Lluch, D. L., Barrachina, A. A. C., \& Murcia, P. L. (2020). Valorization of Prickly Pear [Opuntia ficusindica (L.) Mill]: Nutritional Composition, Functional Properties and Economic Aspects. 10.5772/intechopen.92009.

Gheribi, R., Habibi, Y., \& Khwaldia, K. (2019). Prickly pear peels as a valuable resource of added-value polysaccharide: Study of structural, functional and film forming properties. International Journal of Biological Macromolecules, 126, 238-245. 10.1016/j.ijbiomac.2018.12.228.

Gobbo-Neto, L., \& Lopes, N. P. (2007). Plantas medicinais: fatores de influência no conteúdo de metabólitos secundários. Quimica Nova, 30(2), $374-381$. Gomez, D. G. (2012). Alimentos funcionales: propiedades saludables, análisis y distribución en alimentos. Aldaba. 36. 10.5944/aldaba.36.2012.20532. 
Heim, K. E., Tagliaferro, A. R., \& Bobilya, D. J. (2002). Flavonoid antioxidants: chemistry, metabolism and structure-activity relationships. The Journal of Nutritional Biochemistry, 13(10), 572-584. 10.1016/s0955-2863(02)00208-5.

Hussein, R., \& A. El-Anssary, A. (2019). Plants Secondary Metabolites: The Key Drivers of the Pharmacological Actions of Medicinal Plants. Herbal Medicine. 10.5772/intechopen.76139.

Instituto Brasileiro de Geografia e Estatística IBGE - Censo Agropecuário. (2017).

Isah, T. (2019). Stress and defense responses in plant secondary metabolites production. Biological Research, 52(39). https://doi.org/10.1186/s40659-019-02463.

Izuegbuna, O., Otunola, G., \& Bradley, G. (2019). Chemical composition, antioxidant, antiinflammatory, and cytotoxic activities of Opuntia stricta cladodes. PLOS ONE, 14(1), 01-27. Doi.org/10.1371/journal.pone.0209682.

Kauthale, V., Aware, M., \& Punde, K. (2017). Cactus an Emerging Fodder Crop of Arid and semi-Arid India. BAIF Development Research Foundation Central Research Station, Urulikanchan, Dist- Pune 412.

Kıvrak, Ş., Kıvrak, İ., \& Karababa, E. (2018). Analytical evaluation of phenolic compounds and minerals of Opuntia robusta J.C. Wendl. and Opuntia ficusbarbarica A. Berger. International Journal of Food Properties, 21(1), 229-241. 10.1080/10942912.2018.1451342.

Knupp, L. S., Carvalho, F. F. R., Cannas, A., Marcondes, M. I., Silva, A. L., Francesconi, A. H. D., Cruz, G. R. B., Atzori, A. S., Gaspa, G., \& Costa, R. G. (2019). Meta-analysis of spineless cactus feeding to meat lambs: performance and development of mathematical models to predict dry matter intake and average daily gain. Animal, 13 (10), 2260-2267. 10.1017/S1751731119000326.

Ku-Vera, J. C., Jiménez-Ocampo, R., Valencia-Salazar, S. S., Montoya-Flores, M. D., Molina-Botero, I. C., Arango, J., Gómez-Bravo, C. A., Aguilar-Pérez, C. F., \& Solorio-Sánchez, F. J. (2020). Role of Secondary Plant Metabolites on Enteric Methane Mitigation in Ruminants. Front. Vet. Sci. 7, 584. 10.3389/fvets.2020.0058

Lima Neto, G. A., Kaffashi, S., Luiz, W. T., Ferreira, W. R., Silva, Y. S. A. D., Pazin, G. V., \& Violante, I. M. P. (2015). Quantificação de metabólitos secundários e avaliação da atividade antimicrobiana e antioxidante de algumas plantas selecionadas do Cerrado de Mato Grosso. Rev. Bras. Pl. Med., 17(4), 1069-1077. http://dx.doi.org/10.1590/1983-084X/14_161.

Lira, M. A., Santos, M. V. F., \& Dias, F. M. (2017). Histórico e importância da palma. In: Cadernos do Semiárido. Palma forrageira: cultivo e uso. 1 (7), 19-61.

López-Palacios, C. \& Peña-Valdivia, C. B. (2020). Screening of secondary metabolites in cladodes to further decode the domestication process in the genus Opuntia (Cactaceae). Planta, 251(74), 2-14. 10.1007/s00425-020-03371-9.

Mabrouki, L., Zougari, B., Bendhifi, M., \& Borgi, M. A. (2015). Evaluation of antioxidant capacity, phenol and flavonoid contents of Opuntia streptacantha and Opuntia ficus indica fruits pulp. Revue Nature \& Technologie. C- Sciences de l'Environnement, 13(1) 02-08.

Mannelli, F., Cappucci, A., Pini, F., Pastorelli, R., Decorosi, F., Giovannetti, L., Mele, M., Minieri, S., Conte, G., Pauselli, M., Rapaccini, S., Viti, C., \& Buccioni, A. (2018). Effect of different types of olive oil pomace dietary supplementation on the rumen microbial community profile in Comisana ewes. Scientific Reports, 8, 8455. https://doi.org/10.1038/ s41598-018-26713-w.

Marques, O. F. C., Gomes, L. S. P., Mourthé, M. H. F., Braz, T. G. S., \& Pires Neto, O. S. (2017). Palma forrageira: cultivo e utilização na alimentação de bovino. Cad. Ciênc. Agra., 9(1), 75-93.

McGehee, D. L., Alimohammadi, M., \& Khodakovskaya, M. V. (2019). Carbon-based nanomaterials as stimulators of production of pharmaceutically active alkaloids in cell culture of Catharanthus roseus. Nanotechnology, 30(27), 275102. 10.1088/1361-6528/ab1286.

Monteiro, C. C. F., Ferreira, M. A., Véras, S. C. A., Guido, S. I., Almeida, M. P., Silva, R. C., \& Inácio, J. G. (2018). A new cactus variety for dairy cows in areas infested with Dactylopius opuntiae. Animal Production Science, 1(1), A-G. 10.1071/AN17256.

Moze, S., Polak, T., Gašperlin, L., Koron, D., Vanzo, A., Poklar Ulrih, N., \& Abram, V. (2011). Phenolics in Slovenian Bilberries (Vaccinium myrtillus L.) and Blueberries (Vaccinium corymbosum L.). Journal of Agricultural and Food Chemistry, 59(13), 6998-7004. 10.1021/jf200765n.

Msaddak, L., Abdelhedi, O., Kridene, A., Rateb, M., Belbahri, L., Ammar, E., Nasri, M., \& Zouari, N. (2017). Opuntia ficus-indica cladodes as a functional ingredient: bioactive compounds profile and their effect on antioxidant quality of bread. Lipids in Health and Disease, 16(32), 1-8. 10.1186/s12944-016-0397y.

Naczka, M., \& Shahidib, F. (2004). Extraction and analysis of phenolics in food. Journal of Chromatography, 1054, 95-111. 10.1016/j.chroma.2004.08.059.

Nazareno, M. A. (2017). Nutritional properties and medicinal derivatives of fruits and cladodes. In: IX International Congress On Cactus Pear And Cochineal CAM crops for a hotter and drier world Coquimbo, Chile, 26-30.

Nefzaou, A., Louhaichi, M., \& Ben Salem, H. (2014). Cactus as a tool to mitigate drought and to combat desertification. Journal of Arid Land Studies, 24(1), 121-124.

Ng, M. L., Sasidharan, S., Shanmugapriya, S., Soundararajan, V., Chen, Y., \& Seong, L. G. (2018). Role Of Reactive Oxygen Species (ROS) In Aging And Aging-Related Diseases. Research Journal of Pharmaceutical, Biological and Chemical Sciences, 9 (6), $44-51$.

Ochoa, M.J., \& Barbera, G. (2017). History and economic and agro-ecological importance. In: IX international congress on cactus pear and cochineal cam crops for a hotter and drier world Coquimbo, Chile, 26-30.

Oliveira, A. S. C., Cavalcante Filho, F. N., Rangel, A. H. N., \& Lopes, K. B. P. (2011). A palma forrageira: alternativa para o semiárido. Revista Verde, 6 (3), $49-58$. 
Oliveira, J. P. F. (2017). Palma forrageira em substituição à cana-de-açúcar para ovinos em terminação.

Oliveira, V. S., Ferreira, M. A., Guim, A., Modesto, E. C., Arnaud, B. L., \& Silva, F. M. (2007). Substituição total do milho e parcial do feno do capim-tifton por palma forrageira em dietas para vacas em lactação. Produção, composição do leite e custos com alimentação. R. Bras. Zootec., 36 (4), $928-935$.

Osuna-Martínez, U., Reyes-Esparza, J., \& Rodríguez-Fragos, L. (2014). Cactus (Opuntia ficus-indica): A Review on its Antioxidants Properties and Potential Pharmacological Use in Chronic Diseases. Nat Prod Chem Res, 2 (6), 2-8. 10.4172/2329-6836.100015.

Pereira, A. S., Shitsuka, D. M., Parreira, F. J., \& Shitsuka, R. (2018). Metodologia da pesquisa científica.

Pessoa, D. V., Andrade, A. P., Magalhães, A. L. R. Teodoro, A. L., Santos, D. C., Araújo, G. G. L., Medeiros, A. N., Nascimento, D. B., Valença, R. L., \& Cardoso, D.B. (2020). Forage cactus of the genus Opuntia in different with the phenological phase: Nutritional value. Journal of Arid Environments, 181, 104243. doi.org/10.1016/j.jaridenv.2020.104243.

Pooja, S., \& Vidyasagar G. M. (2016). Phytochemical screening for secondary metabolites of Opuntia dillenii Haw. Journal of Medicinal Plants Studies, 4(5), $39-43$.

Rezende, F. M., Véras, A. S. C., Siqueira, M. C. B., Conceição, M. G., Lima, C. L., Almeida, M. P., Mora-Luna, R. E., Neves, M. L. M. W., Monteiro, C. C. F., \& Ferreira, M. A. (2020). Nutritional effects of using cactus cladodes (Opuntia stricta Haw Haw) to replace sorghum silage in sheep diet. Tropical Animal Health and Production, 10.1007/s11250-020-02213-w.

Robles-Zepeda, R. E., Jiménez-Estrada, M., Navarro-Ocaña, A., Saad-Villegas, I., Brunner, I., \& Ruiz-Bustos, E. (2009). Secondary metabolites induction in Mammillaria huitzilopochtli (Cactaceae) and evaluation of the fungicidal activity. African Journal of Biotechnology, 8 (16), $3874-3878$.

Rocchetti, G., Pellizzoni, M., Montesano, D., \& Lucini, L. (2018). Italian Opuntia ficus-indica Cladodes as Rich Source of Bioactive Compounds with HealthPromoting Properties. Journal Foods, 7(24), 2-12. Doi:10.3390/foods7020024.

Rocha, J. E. S. (2012). Palma Forrageira no Nordeste do Brasil: Estado da Arte. Embrapa Caprinos e Ovinos, Documento 106. http://www.cnpc.embrapa.br/publicacoes/.

Sáenz, C. (2017). Processing and utilization of fruit, cladodes and seeds. In: IX International Congress on Cactus Pear And Cochineal CAM crops for a hotter and drier world Coquimbo, Chile, 26-30.

Santos, D. S., \& Rodrigues, M. M. F. (2017). Atividades farmacológicas dos flavonoides: um estudo de revisão. Estação Científica, 7(3), 29-35. 10.18468/estcien.2017v7n3.p29-35.

Serra, A. T., Poejo, J., Matias, A. A., Bronze, M. R., \& Duarte, C. M. M. (2013). Evaluation of Opuntia spp. derived products as antiproliferative agents in human colon cancer cell line (HT29). Food Research International, 54(1), 892-901. dx.doi.org/10.1016/j.foodres.2013.08.043.

Shetty, A. A., Rana, M. K., \& Preetham, S. P. (2012). Cactus: a medicinal food. Journal of Food Science and Technology, 49 (5), 530-536. 10.1007/s13197011-0462-5.

Silva, A. L. L., Araujo, M. G. S., Bastos, M. L. A., Bernardo, T. H. L., Oliveira, J. F. S., Silva-Junior, E. F., Santos-Junior, P. F. S., Araujo, M. V., AlexandreMoreira, M. S., Araújo-Júnior, J. X., \& Verissimo, R. C. S. S. (2016). Avaliação da atividade antibacteriana, citotóxica e antioxidante da espécie vegetal Opuntia cochenillifera (L.) Mill. Rev. Bras. Pl. Med., 18(1), 307-315. http://dx.doi.org/10.1590/1983-084X/15_145.

Silva, E. T. S., Melo, A. A. S., Ferreira, M. A., Oliveira, J. C. V., Santos, D. C., Silva, R. C., \& Inácio, J. G. (2017). Acceptability by Girolando heifers and nutritional value of erect prickly pear stored for different periods. Pesq. agropec. bras., 52(9), 761-767. 10.1590/S0100-204X2017000900008.

Silva, R. B., Pereira, M. N., Araujo, R. C., Silva, W. R., \& Pereira, R. A. N. (2019). A blend of essential oils improved feed efficiency and affected ruminal and systemic variables of dairy cows. Translate basic science to industry innovation, 4 (1), 1-12. 10.1093/tas/txz183.

Silva, R. C., Ferreira, M. A., Oliveira, J. C. V., Santos, D. C., Gama, M. A. S., Chagas, J. C. C., Inácio, J. G., Silva, E. T. S., \& Pereira, L. G. R. (2018). Orelha de Elefante Mexicana (Opuntia stricta [Haw.] Haw.) spineless cactus as an option in crossbred dairy cattle diet. South African Journal of Animal Science, 48(3), 516-525. http://dx.doi.org/10.4314/sajas.v48i3.12.

Smida, A., Ncibi, S., Taleb, J., Ben Saad, A., Ncib, S., \& Zourgui, L. (2017). Immunoprotective activity and antioxidant properties of cactus (Opuntia ficus indica) extract against chlorpyrifos toxicity in rats. Biomedicine \& Pharmacotherapy, 88, 844-851. 10.1016/j.biopha.2017.01.105.

Soares, S. E. (2002). Ácidos fenólicos como antioxidantes. Rev. Nutr., 15 (1), 71-81.

Stintzing, F. C., \& Carle, R. (2005). Cactus stems (Opuntias pp.): A review on their chemistry, technology, and uses. Mol. Nutr. Food Res., 49, 175-194. $10.1002 / \mathrm{mnfr} .200400071$

Sun, H. X.; Zhong, R. Z.; Liu, H. W. Wang, M. L., Sun, J. Y., \& Zhou, D. W. (2015). Meat quality, fatty acid composition of tissue and gastrointestinal content, and antioxidant status of lamb fed seed of a halophyte (Suaeda glauca). Meat Science, 100, 10-16.

Tahir, H. E., Xiaobo, Z., Komla, M. G., \& Mariod, A. A. (2019). Nopal Cactus (Opuntia ficus-indica (L.) Mill) as a Source of Bioactive Compounds. IN: Wild Fruits: Composition, Nutritional Value and Products. 1(26), 333-355. Doi:10.1007/978-3-030-31885-7.

Taiz, L., \& Zaiger, E. (2006). Fisiologia vegetal. (3a ed.), Artimed.

Taiz, L., Zeiger, E., Moller, I. M., \& Murphy, A. (2017). Fisiologia e desenvolvimento vegetal. 6, 858.

Terço, J. W. S., \& Lima, R. A. (2016). Identificação das classes de metabólitos secundários no extrato etanólico dos frutos e folhas de solanum paniculatum. L. Journal of Basic Education, Technical and Technological, 3(2), 92-99. periodicos.ufac.br/index.php/SAJEBTT/article/view/431. 
Research, Society and Development, v. 10, n. 2, e53910212809, 2021

(CC BY 4.0) | ISSN 2525-3409 | DOI: http://dx.doi.org/10.33448/rsd-v10i2.12809

Valenzuela-Grijalva, N. V., Pinelli-Saavedra, A., Muhlia-Almazan, A., Domínguez-Díaz, D., \& González-Ríos, H. (2017). Dietary inclusion effects of phytochemicals as growth promoters in animal production. Journal of Animal Science and Technology, 59(8), 2-17. DOI 10.1186/s40781-017-0133-9.

Vasta, V., Daghio, M., Cappucci, A., Buccioni, A., Serra, A., Viti, C., \& Mele, M. (2019). Invited review: Plant polyphenols and rumen microbiota responsible for fatty acid biohydrogenation, fiber digestion, and methane emission: Experimental evidence and methodological approaches. Journal of Dairy Science, 102(5), 3781-3804. https://doi. org/10.3168/jds.2018-14985.

Ventura-Aguilar, R. I., Bosquez-Molina, E., Bautista-Baños, S., \& Rivera-Cabrera, F. (2017). Cactus stem (Opuntia ficus-indica Mill): anatomy, physiology and chemical composition with emphasis on its biofunctional properties. J. Sci. Food Agric. 97, 5065-5073. DOI:10.1002/jsfa.8493.

Vidal, I. A. F., Ratts, N. P., Queiroz, F. B., Alves, A. B. C., \& Silva, R. E. R. (2019). Percepção dos profissionais da estratégia de saúde da família no município de Crato-CE sobre fitoterapia. Saúde em Redes, 5(2), 39-46. hp://dx.doi.org/10.18310/2446-4813.2019v5n2p39-46.

Vila Nova, S. R., Barros, J. G., Paixão, A. E. A., Tonholo, J., \& Uchoa, S. B. B. (2017). Palma forrageira: evidências de sua utilização econômica. Cad. Prospec., 10(4), 738-753. http://dx.doi.org/10.9771/cp.v10i4.22939.

Willcox, J. K., Ash, S. L., \& Catignani, G. L. (2004). Antioxidants and Prevention of Chronic Disease. Critical Reviews in Food Science and Nutrition, 44 (4), 275-295. 10.1080/10408690490468489.

Yáñez-Ruiz, D. R., Scollan, N. D., Merry, R. J., \& Newbold, C. J. (2006). Contribution of rumen protozoa to duodenal flow of nitrogen, conjugated linoleic acid and vaccenic acid in steers fed silages differing in their water-soluble carbohydrate content. British Journal of Nutrition, 96(5), 861-869. https://doi.org/10.1017/bjn20061927.

Yáñez-Ruiz, D. R., \& Belanche, A. (2020). Plant secondary compounds: beneficial roles in sustainable ruminant nutrition and productivity. Plant secondary compounds Chapter 10.19103/AS.2020.0067.25.

Zeghad, N., Ahmed, E., Belkhiri, A., Heyden, Y. V., \& Demeye, K. (2019). Antioxidant activity of Vitis vinifera, Punica granatum, Citrus aurantium and Opuntia ficus indica fruits cultivated in Algeria. Heliyon, 5(2), 01575. https://doi.org/10.1016/j.heliyon.2019.e01575. 